\title{
Risk and Equity Release Mortgages in the UK
}

\author{
Tripti Sharma $^{1} \cdot$ Declan French $^{2}$ (1) $\cdot$ Donal McKillop $^{2}$
}

Accepted: 11 September 2020 / Published online: 17 September 2020

(C) The Author(s) 2020

\begin{abstract}
Accessing elderly housing wealth through equity release mortgages (ERMs) continue to be the focus of policy debates about how to pay for social care and how to support retirement incomes in the UK. We demonstrate in this paper that the spatial concentration of this market in just a few regions is not due to demand but to the risks faced by suppliers. We show that by ignoring regional variations in No Negative Equity Guarantee risk in national pricing models providers cannot profitably supply these products outside areas of high house price growth. We also show that EU Solvency II capital requirements provide a further disincentive to supply ERMs in these areas. Government subsidies to product provision are also modelled and shown to be infeasibly high. We therefore conclude that the government policy focus on equity release as a means of tackling the challenges of an ageing population is misplaced.
\end{abstract}

Keywords Reverse mortgages $\cdot$ Equity release $\cdot$ No negative equity guarantee $\cdot$ Solvency II JEL classification G21 $\cdot \mathrm{G} 22 \cdot \mathrm{J} 14$

\section{Introduction}

Many older people in the UK have experienced significant house price growth and are increasingly been encouraged by government to see their home as a means to support retirement incomes and to pay for social care. We argue in this paper that the provision of financial products such as equity release mortgages (ERM) is so inherently risky that

Electronic supplementary material The online version of this article (https://doi.org/10.1007/s11146-02009793-2) contains supplementary material, which is available to authorized users.

Declan French

declan.french@qub.ac.uk

1 Cork University Business School, University College Cork, College Road, Cork, Ireland

2 Queen's Management School, 185 Stranmillis Road, Belfast BT9 5EE, UK 
elderly homeowners in most regions of the UK could not use their home in this way even with government subsidies.

Elderly housing assets have been central to policy debates about state funding of social care and retirement planning over the past decade. Currently, property wealth is used in means-testing for government support with residential care costs and additional costs are then paid from selling the home or from deferred payments from the estate after death. Recent policy initiatives suggest that state funding could be supplemented by a private insurance scheme potentially sourced from equity release or downsizing (CPS 2019). Housing equity is also seen as having a key role in releasing money to adapt homes for the complex needs of the elderly and to address pension shortfalls (FCA 2017). The House of Lords Ready for Ageing report aimed to work with the financial services industry to help people with housing equity to release it simply without excessive charges or risk (Lords 2013).

However, the equity release market in the UK is still small relative to the more mature US reverse mortgage market despite high elderly homeownership rates and high demand (ERC 2018; FCA 2018). This small market is also spatially concentrated in just a few regions with London, South East and South West making up 59\% of overall lending compared to just 14\% in the North (Key Retirement 2018). French et al. (2018) demonstrate that this market is more active where house prices are high despite strong demand for equity release in other parts of the country where both real estate and non-real estate wealth are lower. The contrast between strong demand but low number of equity release plans sold in the North is also seen in data from the UK Wealth and Assets Survey (fig. 1). The main risk faced by providers is the No Negative Equity Guarantee (NNEG) which ensures the amount to be repaid never exceeds the house value. Authors have found that the NNEG significantly contributes to added insurance premia and loan-to-value amounts (e.g. Nakajima and Telyukova 2014; Pu et al. 2014). Hosty et al. (2008) highlight that weaker house price inflation increases the probability of negative equity. In our study, we demonstrate that the spatial concentration of this market in just a few regions is not due to demand but to the risks faced by suppliers. We show that by ignoring regional variations in NNEG risk in national pricing models providers cannot profitably supply these products outside areas of high house price growth. We also show that EU Solvency II capital requirements provide a further disincentive to supply ERMs in these areas.

We model lump sum ERMs using regional house price indices from government office regions of England and Wales. The pricing framework involves constructing a hedonic house price index for each region and forecasting regional house price inflation by fitting a factor-augmented vector autoregressive model based on macroeconomic variables. We fit the Lee-Carter mortality model to predict future mortality rates (Lee and Carter 1992) and calculate the probability of loan termination. These components are used in an overall pricing model which simultaneously simulates stochastic paths of future regional house price growth rates and mortality rates in order to derive the expected value of the NNEG and mortgage insurance premium against the guarantee in each region. Further, we quantify the risk metrics value-at-risk (VaR) and conditional value-at-risk $(\mathrm{CVaR})$ in all regions using the empirical distributions of actuarial present value of the provider's net payoff from ERMs. Finally, we evaluate how much it would cost the government per scheme in each region to equate provider's expected return in every region to levels in the South East. Our estimates of this subsidy indicate it would be prohibitively large. 


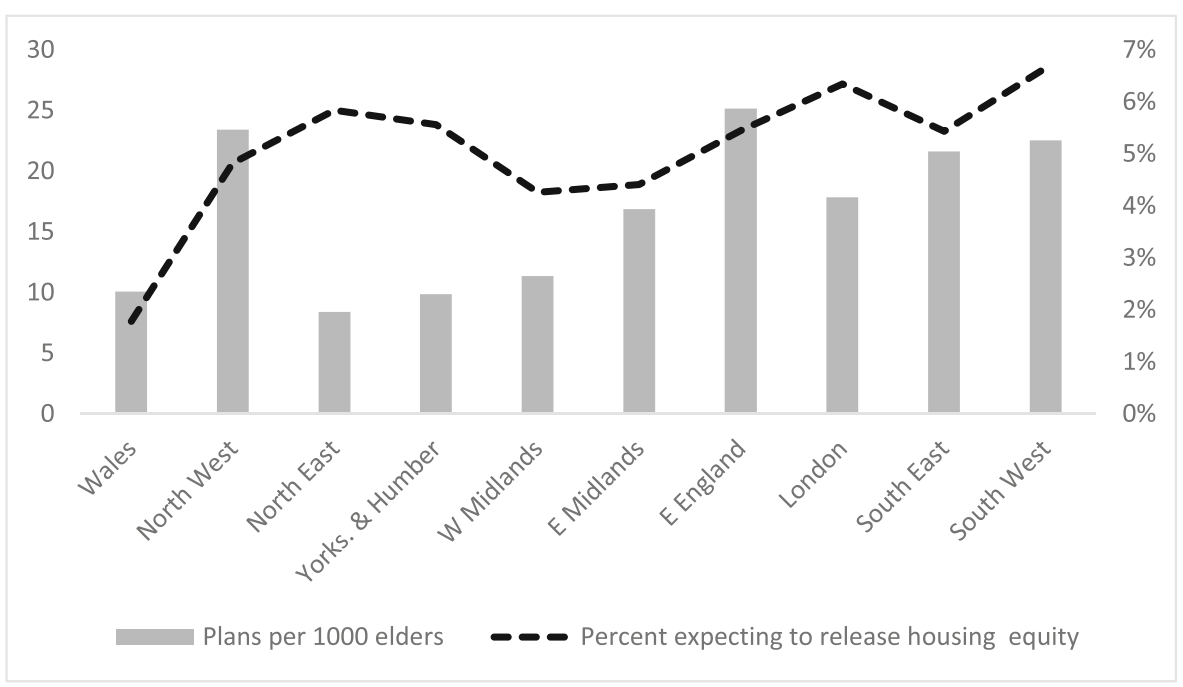

Fig. 1 New equity release plans sold per thousand elders versus demand for equity release. Note: Plans per 1000 elders is proportion of homeowners aged 55+ with equity release arrangement (Source: Wealth and Assets Survey wave 5, 2014-2016). Percent expecting to release housing equity is the proportion of nonretired homeowners within 10 years of state pension age responding "Borrowing against the value of your home" to the question "Which of the options on this card do you expect to use to provide money for your retirement?' (Source: Wealth and Assets Survey wave 1, 2006-2008)

The literature on equity release mortgages has developed following the recent financial crisis. A number of studies have analysed household demand. Shan (2011) finds that the expansion of the US reverse mortgage market can partly be attributed to house price appreciation over time while Haurin et al. (2016) show how house price growth and volatility explains spatial variations in take-up rates. However, French et al. (2018) found that UK demand for equity release does not vary spatially. Research from a supplier's perspective is limited (Lee et al. 2018). A few studies have analysed the risks underlying equity release products and ways to model them efficiently (e.g. Chen et al. 2010; Li et al. 2010; Lee et al. 2012). Our contribution is to show that regional patterns in UK housing equity release can be explained by the riskiness of these products to providers.

The paper is set out as follows. Section 2 provides a background to the UK equity release market and develops a framework for pricing equity release products. Section 3 describes all data used in this study. Section 4 presents results from the longevity and house price models. Results for the value of the NNEG and solvency capital are presented in section 5 with analysis of the effect of subsidizing regional equity release provision. Section 6 concludes.

\section{Background and Theoretical Development}

\section{Background}

There are two main types of equity release scheme products available in the UK market - lifetime mortgages (reverse mortgage in US) and home reversion schemes. Cash can 
be drawn down when required or lent as one lump sum at the start of the contract. As of January 2019, the maximum loan-to-value (LTV) offered to a 55-year old borrower was $18.5 \%, 29.6 \%$ for a 65 -year old customer and $47.1 \%$ if the customer was 90 years old (ERC 2019). The costs involved in setting up an equity release plan include administration fees, solicitor fees, surveyor's fees and adviser's fee and is generally between $£ 2000$ and $£ 3000$. Borrowers are also charged a fixed or variable (but capped) interest rate. Historically, the average interest rate has been around $6.5 \%$ but fell to $5.2 \%$ in the second half of 2018 (ERC 2019).

The first equity release plans for older consumers were launched in 1965 . In the late 1980 s, their reputation was damaged by the misselling of investment bond plans and roll-up plans causing many providers to leave the market while the global financial crisis in 2007-08 also led to the withdrawal of one of the top three equity release providers as capital funding became scarce. The Financial Conduct Authority (FCA) has criticised the market for being neither competitive nor innovative (FCA 2016). Recently, with the implementation of Solvency II under the EU directives, the Prudential Regulatory Authority (PRA) has raised concerns over the risk management of equity release schemes with the NNEG as the main issue (Kenny et al. 2018).

Historically, downsizing has been the main channel of housing equity withdrawal in old age though still not common. Banks et al. (2010) found that only one in every four older British homeowners relocated over ten years compared to about one in three American households. A smaller percentage will have downsized in order to release housing equity.

Both private and government administered reverse mortgages are offered in the US. The plans administered by the Federal Housing Administration (FHA) are Home Equity Conversion Mortgage (HECM) schemes that represent over 95\% of reverse mortgage loans in the US (Moulton et al. 2015). HECM loans are available to mortgage-free homeowners of 62 years and above. The FHA insures the borrowers and the loan providers against the risk of negative equity through a government insurance premium built into the cost of the HECM. The borrowers pay a mortgage insurance premium of $2 \%$ of the appraised value of the house and $1.25 \%$ of the loan balance annually.

Unlike the US reverse mortgage market, the UK equity release market is operated by private insurance companies and retirement product providers. Although not a regulatory requirement, most firms and advisers are members of the Equity Release Council (ERC), a trade body for the UK market. It is compulsory for ERC members to provide the NNEG, and since they dominate the market, the clause has become an industry standard. The risk management of the NNEG risk is undertaken by offering prudent loan-to-value ratios and incorporating a premium in the interest rate charged to the borrower. Although UK premiums are not made public, estimates for the cost of the NNEG as a percentage of the initial lump sum range from $0.1 \%$ to $6.5 \%$ for a 65 -year old female borrower depending on assumptions (Tunaru and Quaye 2019).

\section{Theoretical Model}

We model a single female customer taking out an ERM with a lump sum payment made from the lender to the customer at contract issuance. There are no subsequent payments made to the borrower or repayments made on their behalf over the duration 
of the contract. This type of ERM is known as a lump sum lifetime mortgage and is widely used in the UK (Key Retirement 2018). ${ }^{1}$

Following Shao et al. (2015), the initial loan amount $\left(L_{0}\right)$ grows every quarter at a variable interest rate. ${ }^{2}$ The interest rate charged to the customer against the provision of the NNEG at the beginning of the quarter (Chen et al. 2010) is a sum of the quarterly risk-free rate of return $\left(r_{t}^{(1)}\right)$, which is taken as the one-quarter zero coupon bond yield rate, quarterly lending margin $(\kappa)$ and a quarterly mortgage insurance premium rate $(\pi)$. The outstanding loan amount $\left(L_{T_{x}}\right)$ for a single borrower aged $x$ over a random termination time $\left(T_{x}\right)$ can be expressed as

$$
L_{T_{x}}=L_{0} \exp \left(\sum_{t=1}^{K_{x}+1}\left(r_{t}^{(1)}+\kappa+\pi\right)\right),
$$

where $K_{x}=\left[T_{x}\right]$ represents the completed time of the contract. The initial loan amount is a proportion of the house value at the time of contract initiation referred to as the loanto-value (LTV) ratio.

At contract termination, the borrower repays either an amount equal to $L_{T_{x}}$ or the value of the mortgaged property at that time $H_{T_{x}}$ whichever is smaller. In the former scenario, the contract yields no loss whereas the NNEG applies in the latter case and the difference $\left(L_{T_{x}}-H_{T_{x}}\right)$ is the provider's loss i.e.

$$
\operatorname{Loss}_{T_{x}}=\max \left(L_{T_{x}}-(1-t c) H_{T_{x}}, 0\right)
$$

where $t c$ refers to the transaction cost incurred on the sale of the mortgaged property (Hosty et al. 2008). ${ }^{3}$

The value of the NNEG, therefore, equals the expected present value of the provider's expected future loss. The expression in eq. (3) determines the value of the expected loss (if any) at the end of each quarter until the person's maximum attainable age $\omega$ before discounting it back to the present using the discount factor $v=1 /\left(1+d^{(4)}\right)$. The rate of discounting $\left(d^{(4)}\right)$ was obtained following the methodology outlined in Bracke et al. (2018). ${ }^{4}$

$$
N N E G=\sum_{t=0}^{\omega-x-1} E\left[v^{t+1} q_{x}{ }^{t \mid} \operatorname{Loss}_{t+1}\right]
$$

\footnotetext{
${ }^{1}$ Most other studies have simplified the modelling exercise by assuming the purchaser of the ERM is a single female and have set a maximum attainable age of 105/110 years (Sherris and Sun 2010; Alai et al. 2014; Shao et al. 2015). They argue that this is reasonable since equity release contracts do not terminate until both husband and wife have died and typically females survive longer. Single female borrowers are also the most common type of ERM customers after couples in the UK. In common with other authors, we model lump sum ERMs for convenience even though drawdown ERMs dominate the UK market. This will have the effect of making ERM loans look riskier but as long as drawdown follows a similar pattern in all regions our findings should still hold.

${ }^{2}$ For simplicity, we assume that the loan accumulates at a fixed rate of interest while calculating the value of the NNEG. However, variable rates were used to assess solvency capital requirements.

${ }^{3}$ This pricing model operates under real-world assumptions.

${ }^{4}$ Bracke et al. (2018) estimate implied discount rates by factoring in the long-term rate of real rent growth. For the period 2009 Q2 to 2013, gross discount rates were between $2 \%$ and $7 \%$ for terms less than 45 years. An annualised discount rate of $6.41 \%$ was obtained by taking the midpoint of this range and adding a nominal rental growth of $1.91 \%$ (ONS series D7CE) or $1.57 \%$ per quarter.
} 
The termination term ${ }_{t} q_{x}=P\left(t<T_{x}<t+1\right)={ }_{t} p_{x} q_{x+t}$ refers to the stochastic probability that the contract is active until $t$ but terminates between $t$ and $t+1$. It is assumed that property disposal takes place immediately after the contract terminates.

UK equity release providers undertake the risk management of the NNEG risk by offering prudent LTVs and incorporating a cost against the guarantee in the interest rate charged to the customer known as a mortgage insurance premium (Kenny et al. 2018). ${ }^{5}$ Therefore, if a fixed premium $\pi$ is paid at the beginning of each quarter until the contract terminates the expected present value of all payments equals

$$
M I P=\pi \sum_{t=0}^{\omega-x-1} E\left[p_{x} L_{t} v^{t}\right]
$$

where ${ }_{t} p_{x}$ refers to the probability of the contract being in effect at $t$ and the value of $v^{0}$ equals one. The expected present value of all premiums paid should be enough to cover the expected future loss due to the NNEG. Hence, the value of $\pi$ can be determined by equating eqs. (3) and (4) (Shao et al. 2015).

We calculate the empirical distribution of the present value of the provider's net payoff following Alai et al. (2014) to calculate VaR and CVaR risk metrics. VaR informs the worst-case cash flow at a $99.5 \%$ confidence level, CVaR estimates the provider's expected shortfall. This allows us to study the impact of the NNEG on the provider's net payoff from equity release mortgages and ultimately their solvency levels.

The presence of the NNEG reduces the terminal value of the cash flow. The ERM cash flow was computed as the discounted value of the difference between the loan balance at the end of the contract capped at the realised house value net of the transaction cost and the cost of raising the initial loan amount $\left(L_{0}\right)$ at random risk free rate of returns. This is similar to calculating the economic value (EV) of ERMs with respect to the Prudential Regulatory Authority's (PRA) proposed treatment of these products under the new Solvency II regime. ${ }^{6}$ Under the assumption that the lender finances the loan by leveraging, the value of a lender's final payoff from an equity release mortgage equals

$$
E V=\sum_{t=0}^{\omega-x-1}\left[v^{t+1} q_{x}\left[\min \left(L_{t+1},(1-t c) H_{t+1}\right)-L_{0} \exp \left(\sum_{j=0}^{t+1} r_{j}^{(1)}\right)\right]^{t \mid}\right]
$$

\footnotetext{
${ }^{5}$ Unlike the US, the UK market does not have a predetermined fixed premium rate and the MIP rate is embedded in the interest rate charged to customers. Reverse mortgage borrowers in the US pay an upfront mortgage insurance premium of $2 \%$ of the appraised value of the house and $1.25 \%$ of the loan balance annually (Nakajima and Telyukova 2017). However, since no repayment is made until the loan terminates, all accrued interests and charges add up to the loan balance and are recovered through the sale of the house (Davidoff 2015).

${ }^{6}$ The matching adjustment under Solvency II provides reliefs to insurance companies in solvency capital evaluations against holding certain types of assets that match the cashflows of long-term liabilities such as life annuities (Swain and Swallow 2015). Practitioners have identified equity release mortgages as appropriate investments in order to pay off their annuity liabilities with the proceeds of these products. However, ERMs are classified as long-term risky assets due to the NNEG (PRA 2016). Therefore, the PRA requires firms to conduct the economic value test of ERMs. Upon failure of the test, the firms are required to adjust the structure of ERMs and capital evaluations (PRA 2018). The economic value is defined as the discounted value of the best estimate cash flows, less expenses, less NNEG, less other risks such as prepayment of the loan (Kenny et al. 2018).
} 
In summary, the random variables in this model are - realised house value in a region upon contract termination, the time to maturity and the movement of the risk-free rate of return. The structure of one-quarter risk-free rates was modelled using the CoxIngersoll-Ross model (Cox et al. 1985). ${ }^{7}$ The regional house price and termination models are outlined in the following sub-sections.

\section{Modelling Regional House Price Risk}

The house price model involves two parts. The first consists of constructing hedonic house price indices for modelling the uncertainty of the changes in house prices located in an area while the second involves forecasting house price inflation for which we use the factoraugmented vector autoregressive model (FAVAR) developed by Bernanke et al. (2005).

\section{The Hedonic House Price Index}

Hedonic regression models are a common approach for evaluating the implicit value of housing characteristics (Hill 2013). Hedonic models have several functional forms but the log-linear approach is standard because of the ease of estimating the house price index (de Haan and Diewert 2013) and is used in the UK to construct base-weighted house price indices (Halifax 2016).

The price of a property $i$ in quarter $t,\left(p_{i}^{t}\right)$, is a function of a fixed number of characteristics $K\left(\beta_{1}, \beta_{2}, \ldots, \beta_{K}\right)$, such that

$$
\ln \left(p_{i}^{t}\right)=\beta_{0}^{t}+\sum_{k=1}^{K} \beta_{k}^{t} Z_{k}+e_{i}^{t}
$$

where $t$ equals 1995 Q1 to $2018 \mathrm{Q} 1, \beta_{0}^{t}$ is the intercept of the regression in $t$ and $e_{i}^{t}$ are random error terms. The expression $Z_{k}$ represents a set of dummy variables that take the value 1 if the property possesses characteristic $k$ or 0 otherwise. The model assumes that the characteristics of the property do not change during the observed period and the implicit value of the house attributes are time-varying reflecting changing consumer tastes and preferences (Chen and Harding 2016). Estimates from eq. (6) were then used to calculate a Laspeyres base-weighted regional house price index by calculating the house price in each quarter as the sum of the implicit value of housing characteristics $k$ in time $t\left(\beta_{k}^{t}\right)$ weighted by the mean of the characteristic variables of the observations in the base period $\left(\bar{Z}_{k}^{0 R}\right)$ in the region $R$. The area-wise real house price index is obtained as the ratio of the house value in a quarter to the value in the base period

$$
H P I_{t r}=\frac{\exp \left(\beta_{0}^{t}+\beta_{0}^{t R}+\sum_{k=1}^{K} \beta_{k}^{t} \bar{Z}_{k}^{0 R}\right)}{\exp \left(\beta_{0}^{0}+\beta_{0}^{0 R}+\sum_{k=1}^{K} \beta_{k}^{0} \bar{Z}_{k}^{0 R}\right)} \times 100
$$

\footnotetext{
${ }^{7}$ Lee et al. $(2012,2018)$ apply the CIR model to three-month Treasury bill yield rates for the purposes of developing risk-neutral solutions to the valuation of equity release mortgages. In this paper, we estimate the model assuming real-world parameters. We estimate the model parameters over a sample of one-quarter zero coupon yield rates from 1975 Q1 to 2015 Q4.
} 
where $\beta_{0}^{t R}$ refers to the region's coefficient. The denominator terms of eq. (7) correspond to the base period Q1 1995.

\section{Forecasting Regional House Price Inflation}

The factor-augmented vector autoregressive model reduces a large set of macroeconomic time series to a small number of common components which are then used to forecast real house price growth rates (Das et al. 2010). A matrix of $z$ latent common factors $F_{t}$ is extracted such that for each time series $x_{i t}$

$$
x_{i t}=\lambda_{i} F_{t}+\xi_{i t}
$$

where $\lambda_{i}$ represents a matrix of time series-specific factor loadings and $\xi_{i t}$ signify the idiosyncratic components. The factors are then forecasted and combined with loadings to forecast each separate time series.

For each region $j$, the retained common factors and the regional house price growth rates were used in a vector autoregressive model to predict house price inflation (HPI) $y_{j t}$

$$
y_{j, t+h}=\alpha_{0}+\alpha_{1}(L)^{\prime} F_{t}+\alpha_{2}(L)^{\prime} y_{j t}+\epsilon_{j, t+h}
$$

where $h$ is the time horizon and $L$ is the lag operator. The number of lags were obtained as outlined in Tsay (2010) by selecting lag length using the information criteria - Akaike information criterion (AIC) and Schwarz-Bayesian information criterion (SBIC) - and validating the model by checking for uncorrelated errors and stability. If they differed the lag length was decided based on the minimum mean absolute forecast error (MAD) calculated by comparing the predicted HPI in the region against the returns supplied by the Nationwide house price index for the out-of-sample period - 2017 Q1 to 2019 Q1.

\section{Modelling Termination Risk}

We assume the contract terminates upon the death of the customer. ${ }^{8,}{ }^{9}$ Therefore, the Lee-Carter model is fit to the observed age-specific death rates in order to project mortality rates and derive survival probabilities.

The Lee-Carter model takes the form -

$$
\ln \left(m_{x, t}\right)=a_{x}+b_{x} \kappa_{t}+\varepsilon_{x, t}
$$

where $\ln$ is the natural $\log$ operator and $m_{x, t}$ is the central death rate for females observed in the human mortality database at age $x$ and time $t$. The central death rate is the average number of deaths between age $x$ and $x+1$. Notation $a_{x}$ accounts for the

\footnotetext{
${ }^{8}$ Early repayment of the loan reduces the NNEG risk but this could not be modelled due to a lack of data. Further, termination triggered upon movement of the customer to a care home is approximately the same as termination on death as life expectancy in these facilities is short (Forder and Fernandez 2011; Kenny et al. 2018).

${ }^{9}$ Shao et al. (2015) consider entry into long-term care as well as refinancing and pre-payment risk in their empirical work but conclude that the impact of idiosyncratic house price risk and longevity risk on NNEG is much larger than that of non-mortality termination triggers.
} 
average differences in mortality by age. The parameter $b_{x}$ shows the pattern of deviation in mortality at age $x$ corresponding to the changes in the time-varying mortality level index $\left(\kappa_{t}\right)$. A standard technique for estimating $b_{x}$ and $\kappa_{t}$, is to apply singular value decomposition (SVD) to a matrix of logarithms of age-specific death rates $m_{x, t}$ net of the matrix of $a_{x}$. The kappa $\kappa_{t}$ is modelled using a random walk with drift i.e. ARIMA $(0,1,0)$ as in Lee and Carter (1992).

$$
\kappa_{t}=\kappa_{t-1}+c+e_{t}
$$

To generate random mortality rates, we require time-varying forecast errors, which involve standard errors produced by parameters $a_{x}, b_{x}, \kappa_{t}$ and $\varepsilon_{x, t}$. The errors in forecasting the mortality index dominate the errors in fitting the overall mortality matrix where, for a forecast interval $s$, the standard error of the forecast of $\kappa_{t}$ equals $\sqrt{s \times s e_{e}^{2}+s \times s e_{c}^{2}} \cdot{ }^{10}$ In order to calculate the termination probability, we require the probability $q_{x}$ that a borrower aged $x$ dies before she reaches $x+1$. Following ONS's methodology (ONS 2019), $q_{x}$ is estimated as

$$
q_{x}=\frac{\hat{m_{x, t}}}{\left(1+\left(1-\alpha_{x}\right) \hat{m_{x, t}}\right)}=\frac{2 \times \hat{m_{x, t}}}{2+\hat{m_{x, t}}}
$$

where $\alpha_{x}$ is the average life expectancy between the interval $[x, x+1)$. Finally, the probability that the equity release contract terminates between times $t$ and $t+1$ equals ${ }_{t} \mid q_{x}$.

\section{Data}

Three main data sets are used in the house price model. The first set on property transactions comes from the HM Land Registry Price Paid data. This data tracks residential property sales in England and Wales submitted to the HM Land Registry for registration on a monthly basis since 1995. It includes information on the sale price, house types - detached, semi-detached, terraced or flat/maisonette - whether the property is newly built or old, whether it is sold on freehold or leasehold basis and whether it is sold at a full market value or a second-hand value (power sales/repossessions, buy-to-let and non-private sales). Additionally, the data contains the complete address of the traded properties including the postcode and details such as the street name, locality, town/city, district and county. The transaction records until March 2018 were used in this study.

Government office regions (GOR) and area classification of the traded properties were determined using the National Statistics Postcode Lookup (NSPL). The area classifications based on NSPL were - constrained city dwellers, cosmopolitans, ethnicity central, hard-pressed living, multicultural metropolitans, rural residents, suburbanites and urbanites. Hedonic models typically use house characteristics data sourced

\footnotetext{
${ }^{10}$ The underlying assumption is that the innovation terms produced by the random walk model are independent of the errors in estimating the drift term.
} 
from estate agent records but these data tend to be influenced by their lending policies and regional presence in the market (Chandler and Disney 2014). In contrast, the HM Land Registry data is comprehensive covering all residential property sales.

The third set incorporates 32 quarterly UK macroeconomic time series observed from Q3 1997 to Q4 2016. They were obtained from the ONS economic database. Standard transformations were used where necessary to make the time series stationary. Appendix 1 contains a list of these times series along with the transformation applied.

The England and Wales mortality data used in this study come from the Human Mortality Database (HMD) collected by the Department of Demography at the University of California and the Max Planck Institute for Demographic Research in Rostock, Germany. We used female central mortality rates observed from 1950 to 2016 at single ages 45 to 109 years.

\section{Preliminary Analyses: House Price and Mortality Models}

\section{House Price Models}

Table 1 provides descriptive statistics for the sample of residential property transactions in England and Wales. Overall, the sample consists of 23 million observations after matching the region and area classifications from the national postcode database.

Figure 2 shows the plot of regional house price indices following the methodology described in section 2.3.1. The north-south difference in regional house price growth rates is very clear. Growth in house prices in London and the South East are above the national average whereas they are far lower in the North East, and Yorkshire and Humber. Additionally, the impact of economic events such as the global financial crisis is seen across all regions.

To forecast regional house price inflation by fitting an FAVAR model, we first need to extract the common factors from the time series of macroeconomic variables in Appendix 1 through principal component analysis. The in-sample period used is 1997 Q3 to 2016 Q4 as this is the period for which all macroeconomic time series were available. The eight common components with eigenvalue $\lambda>1$ were retained following the conventional principal component analysis stopping rule (Jackson 1993). These factors explain $75 \%$ of the common variance between the underlying variables. The last column of Table 2 provides annualised mean of forecasts of HPI over a horizon of 40 years (column 3) obtained using the estimated FAVAR models with order specifications given in column 2. ${ }^{11}$ As seen, the forecasts across all regions are lower than the

\footnotetext{
${ }^{11}$ These simulations incorporated parametric uncertainty in the following way. The coefficient of each lag variable was randomised using the standard error estimated in the FAVAR model for that variable. Random errors were generated using the root mean square error of the model. Usually, the Cholesky decomposition is required for simulating future predictions. However, it was not feasible to incorporate large order matrices from Stata to MATLAB simulations for 11 different models. The mean of the resultant standard errors of HPI over a short-run horizon of 6 years $/ 24$ quarters $(h=1,2, \ldots, 24)$ was $5.6 \%$ in the North East and $4.2 \%$ in London. Whereas, the mean of standard errors including the Cholesky decomposition was $3.4 \%$ and $1.5 \%$ respectively.
} 
sample mean of historical growth rates in keeping with current stalled house price growth indicated by UK experts. ${ }^{12,13}$ The lower forecasts also seem sensible in consideration with the low house price growth rates expected by UK 'fiscal watchdogs' over the next few years. ${ }^{14}$ In addition, the forecasts exhibit the same north-south trends observed historically.

\section{Mortality Model}

We focus on female elderly mortality rates between ages 45 and 109 years for England and Wales. The Lee-Carter model described in section 2.4 was fitted to these data in order to project mortality rates and derive survival probabilities. Fig. 3 displays the survival probability curve based on the estimated parameters from this model along with $95 \%$ confidence bounds. ${ }^{15}$ The curve is flat at mid-ages but declines sharply at older ages. ${ }^{16}$

For the purposes of modelling equity release contracts, future mortality rates are simulated by allowing for parametric uncertainty and using the estimated parameters of the Lee-Carter model. The average number of years to contract termination based on stochastic mortality projections was found to be 22.5 years.

\section{Empirical Results}

\section{The Base Case Scenario and Stochastic Modelling}

In the base case scenario, we model equity release contracts issued to a typical 65-year old single female borrower with 105 years as the maximum attainable age $(\omega)$. The value of the house at contract issuance $\left(L_{0}\right.$ in (1)) is taken as $£ 215,000$ which is the median of property prices paid on residential transactions in 2016 reported by the Land Registry. The loan amount accumulates at a rate of $1.47 \%$ per quarter based on current rates charged to customers in the UK equity release market (ERC 2018). ${ }^{17}$ The quarterly lending margin $(\kappa)$ was taken as $0.5 \%$ based on the 2017 commercial real estate lending survey of the UK market. ${ }^{18}$ The transaction cost incurred at the time of

\footnotetext{
12 The rate of growth in UK house prices has been the slowest in the last six years in early 2019 (BBC 2019).

${ }^{13}$ Our mean historical HPI of 7.3\% is only slightly lower than the average of 7.4\% we calculate for 1974 Q1 to 2019 Q4 based on the Nationwide UK house price index. UK HPI has been consistently high relative to other OECD countries over this period due to sustained demand for housing, lack of supply, demographic change and competitive mortgage markets (Hilber 2015; Sharma et al. 2018). This trend looks set to continue albeit at a slightly lower rate as the UK government has introduced many housing policies since 2013 to stimulate the housing market and support young people get on the property ladder (Chandler and Disney 2014).

14 The UK fiscal watchdog has downgraded its house price forecasts (Financial Times 2019).

${ }^{15}$ Figures A.1-A.3 in the supplementary appendix display the values of the estimated Lee-Carter parameters.

16 The accuracy of the parameter estimates can be measured by constructing a life table with the out-of-sample predictions of $m_{x, t}$. Following the methodology outlined in ONS (2019), a female who is 65 years in the year 2066 can expect to live until the age of 90.4 years if she experiences the age-specific mortality rates projected for 2066 (based on the estimated model parameters) for the rest of her life. ONS predicts a 65-year old female in 2066 survives until 90 years of age (ONS 2017).

${ }^{17}$ The average rate charged to lifetime mortgage borrowers was $6.20 \%$ pa (January 2016) and $5.96 \%$ pa (July 2016) (ERC 2018). A $6 \%$ annualised rate equates to a quarterly rate of $1.47 \%$.

18 https://www.cass.city.ac.uk/business-services/consulting/research/commercial-real-estate-debt/the-ukcommercial-property-lending-report
} 
Table 1 Descriptive statistics

Hedonic model variables England and Wales (proportions)

\begin{tabular}{|c|c|c|}
\hline \multirow[t]{10}{*}{ Regions } & North East & 0.04 \\
\hline & North West & 0.12 \\
\hline & Yorkshire \& Humber & 0.09 \\
\hline & East Midlands & 0.08 \\
\hline & West Midlands & 0.09 \\
\hline & East England & 0.12 \\
\hline & London & 0.13 \\
\hline & South East & 0.17 \\
\hline & South West & 0.11 \\
\hline & Wales & 0.05 \\
\hline \multirow[t]{4}{*}{ Property types } & Detached houses & 0.23 \\
\hline & Semi-detached houses & 0.28 \\
\hline & Terraced houses & 0.31 \\
\hline & Flats/Maisonettes & 0.18 \\
\hline \multirow[t]{2}{*}{ Age of the property } & Newly built & 0.10 \\
\hline & Old property & 0.90 \\
\hline \multirow[t]{2}{*}{ Tenure } & Freehold & 0.76 \\
\hline & Leasehold & 0.24 \\
\hline \multirow[t]{2}{*}{ Transaction types } & Standard transaction at full market value & 0.98 \\
\hline & Power sale/repossessions/buy-to-let & 0.02 \\
\hline \multirow[t]{8}{*}{ Area classifications } & Constrained city dwellers & 0.05 \\
\hline & Cosmopolitans & 0.07 \\
\hline & Ethnicity central & 0.05 \\
\hline & Hard-pressed living & 0.14 \\
\hline & Multicultural Metropolitans & 0.13 \\
\hline & Rural Residents & 0.10 \\
\hline & Suburbanites & 0.22 \\
\hline & Urbanites & 0.25 \\
\hline \multicolumn{2}{|c|}{ Number of observations } & $23,043,346$ \\
\hline
\end{tabular}

Note: Sample is residential property transactions in England and Wales from 1995 Q1 to 2018 Q1, which was mapped against ONS's postcode lookup data to identify the government office region and the area classification of the observations

house sale (tc in (2)) is taken as $5 \%$ of the realised house value based on the NNEG valuation parameters in IFoA (2014).

We generate random outcomes to determine the effect of random house price growth and loan termination probabilities on ERM pricing for each region. Each randomization gives stochastic paths for future mortality rates based on the Lee-Carter model and the probability of loan termination in each quarter. Simultaneously, random paths are generated for quarterly regional house price growth based on the parameters estimated from the FAVAR model for that region. Therefore, simulated forecasted house price growth will vary around the mean forecasted values given in Table 2 and variances will 


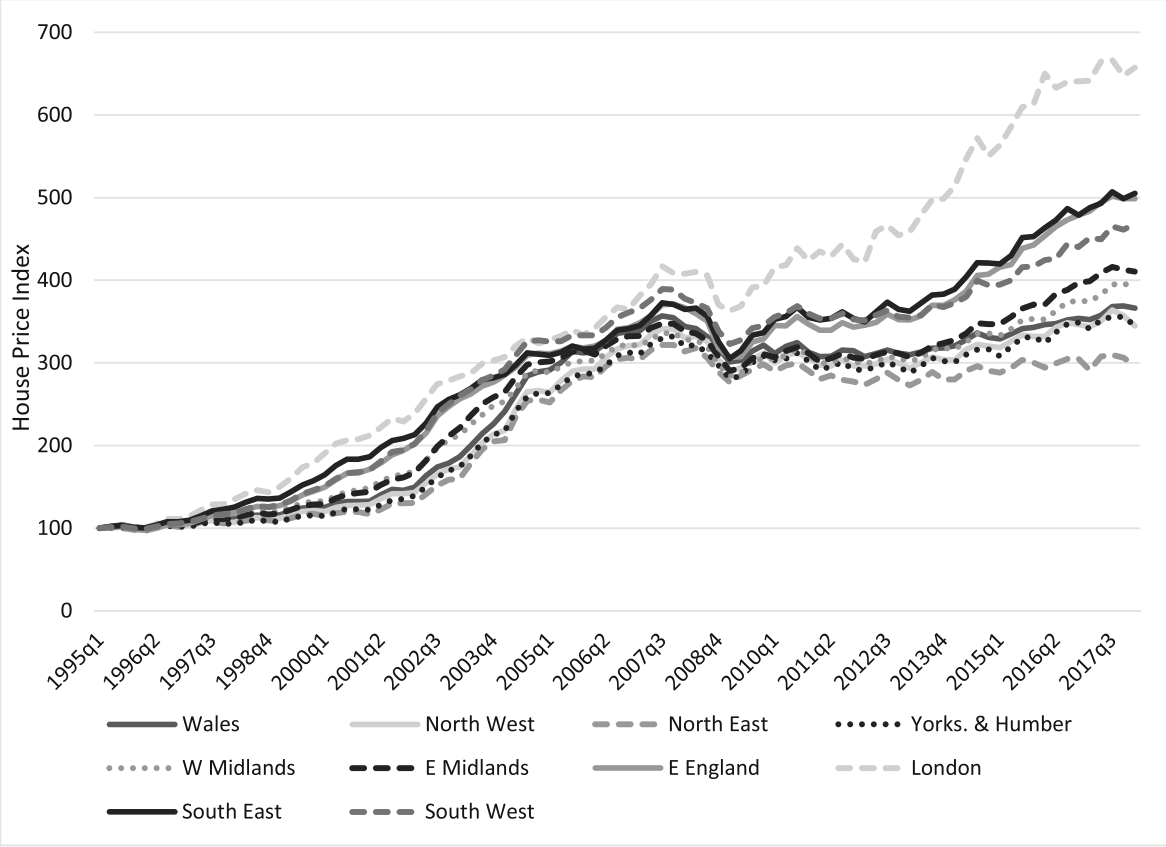

Fig. 2 Hedonic house price index. Note: The index is constructed from 1995 Q1 to 2018 Q1

increase the later the loan terminates. Then the gap between the outstanding loan balance and the projected value of the house is estimated to derive the value of the provider's loss over a horizon of 40 years as in (2). Negative equity becomes more likely when simulated house price growth is low relative to the rate of loan accumulation. The financial value of the risk due to the NNEG equals the expected present value of the provider's loss from (3). The rate of the mortgage insurance premium ( $\pi$ in (4)) is found by equating the value of the NNEG in (3) to the expected present value of all accumulated mortgage insurance premiums in (4). These steps are repeated tenthousand times to generate empirical distributions of the NNEG and MIP rates.

\section{Risk Analysis and Discussion of Regional Variations}

Table 3 reports the mean values of our risk measures - the probability of the occurrence of the NNEG, the NNEG value and the annualised MIP rates. These values indicate the expected financial risk facing providers due to the NNEG and risk-based premium rates required to cover the loss if the contract is issued to a typical borrower. To investigate the impact of varying LTVs on the risk structure, we calculate the risk measure for three loan-to-value ratios - Panel A (30\%), Panel B (40\%) and Panel C (60\%). The table presents results for all regions as well as England and Wales overall.

The results display the impact of regionally varying house price inflation on equity release valuations and indicate that low risk exposure in the South incentivises supply of equity release products there.

The estimates in panel A correspond to the typical LTV of $30 \%$ offered in the UK equity release market to a 65-year old borrower (ERC 2019). From the first column of 
panel A, we can see that the NNEG is rarely invoked in London and the South East. The risk in the South West and East England is moderate with the likelihood of the outstanding loan outstripping house price growth being $8 \%$ and $6 \%$ in each region respectively. However, the risk probabilities become more significant moving towards the Midlands and the North. In particular, approximately one-third of equity release contracts are likely to end up in negative equity in the North East and Yorkshire \& Humber.

Calculating the present value of the NNEG in column 2 of panel A shows that providers can expect to lose $£ 56$ in London or $£ 480$ in the South East on average from their returns on the mortgaged asset should the NNEG apply. ${ }^{19}$ Consequently, the riskadjusted premium required to cover the expected loss/ the NNEG is minimal (just above zero) in these two regions (column 3). However, the financial risks in the north particularly the North East, and Yorkshire and Humber are much larger requiring significant mortgage insurance premium rates to be charged to borrowers against the guarantee. For example, the NNEG is $£ 9351$ in the North East with an annualised premium rate of $0.68 \%$.

Therefore, from a provider's perspective, there is a greater incentive to issue ERMs to homeowners in the south of England where risk exposure is low resulting in the skewed spatial distribution of equity release business we observe in practice. These results reflect a serious miscalculation of the financial risk facing equity release providers when the product is priced at national level especially in the North East where house prices are still below their pre-crash peak (ONS 2018a). ${ }^{20}$ Regional equity release markets are therefore being cross-subsidised.

What is also striking is the variation in risk measures by LTV ratios across the panels. A large amount of equity released at the outset of the contract (high LTV) with a long interest accrual duration reduces the gap between the house value and the outstanding loan amount exposing the product provider to greater financial risks. This is apparent in the valuation results in panels B and C. Although regional variations in the risk measures are in line with the patterns highlighted earlier, we find that their levels are substantially higher in the South at an LTV of $60 \%$ in panel C. For example, the value of the NNEG in the South East in panel C is $£ 6500$ as opposed to $£ 480$ at $30 \%$ LTV. Therefore, our findings suggest that increasing LTVs up to $60 \%$ as suggested by other authors (Fox O’Mahony and Overton 2015) would be infeasible in the UK market. ${ }^{21}$

In Table 3, we assume a uniform value of the house in all regions and therefore there is no difference in the initial loan amount. However, in reality, borrowers have access to a higher amount of home equity in regions with high house values. Therefore, as a robustness check, in Table 4, we present results where the value of the house at the

\footnotetext{
${ }^{19}$ The application of the NNEG does not result in a loss in the usual sense. However, it results in the lender earning a lower return on the mortgaged property than they would have in the absence of the NNEG (IFoA 2014).

${ }^{20}$ In practice, however, there is no regional variation in the cost of the NNEG risk charged to borrowers. The customer brochures from Legal and General, Aviva and Just Retirement - leading ERM providers - indicate the interest rate charged depends only on the borrower's "circumstances" including borrower's age, property value and the type of equity release product.

${ }^{21}$ Fox O'Mahony and Overton (2015) and Andrews and Oberoi (2015) argue that the LTVs offered by the UK market are overly prudent and recommend increasing them. Similarly, Alai et al. (2014) argue that there is scope for offering higher LTVs to younger borrowers by Australian reverse mortgage providers.
} 
Table 2 Historic house price inflation based on Hedonic house price indices and FAVAR model specifications and results

\begin{tabular}{llll}
\hline Region & $\begin{array}{l}\text { Mean house price } \\
\text { inflation (historical) }\end{array}$ & FAVAR lag lengths (2) & $\begin{array}{l}\text { Mean house price } \\
\text { inflation (forecasts) (3) }\end{array}$ \\
\hline North East & $5.8 \%$ & 3 & $4.3 \%$ \\
North West & $6.4 \%$ & 2 & $5.5 \%$ \\
Yorks. \& Humber & $6.5 \%$ & 3 & $5.0 \%$ \\
E Midlands & $7.1 \%$ & 3 & $5.4 \%$ \\
W Midlands & $6.6 \%$ & 2 & $5.9 \%$ \\
East England & $8.0 \%$ & 2 & $6.8 \%$ \\
London & $9.1 \%$ & 2 & $7.8 \%$ \\
South East & $7.8 \%$ & 2 & $6.4 \%$ \\
South West & $7.5 \%$ & 2 & $6.3 \%$ \\
Wales & $6.3 \%$ & 2 & $6.0 \%$ \\
England \& Wales & $7.3 \%$ & 2 & $6.2 \%$ \\
\hline
\end{tabular}

Note: Column (1) shows the mean HPI based on Hedonic house price indices for the in-sample period 1997 Q3 to 2016 Q4. Column (2) displays the lag lengths of region-specific FAVAR models. Column (3) contains the average of the simulated forecasts of house price returns over a horizon of 40 years allowing for parametric uncertainty

beginning of the contract equals the median of the price paid on the residential properties transacted in the region. Results are largely unchanged. In particular, there is almost no change in the risk probabilities and mortgage insurance premium rates in comparison to panels A and B of Table 3. However, the NNEG value is sensitive to the initial value of the house. For example, from panel A of Tables 3 and 4, we can see that the NNEG value reduces from $£ 3439$ to $£ 2251$ in the North West whereas the value of the guarantee increases slightly in London. Since the NNEG value declines with the value of the house, the net effect of the guarantee on returns on the house value will be

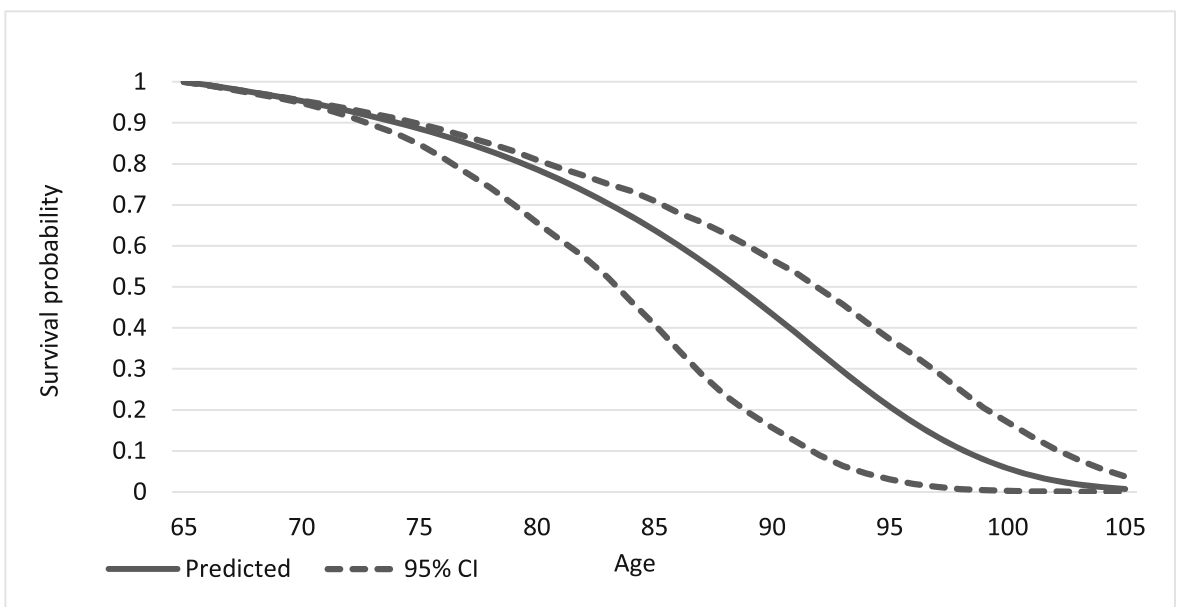

Fig. 3 Simulated survival probabilities for 65-year old females 
almost the same as before. Additionally, the regional variations of the risk measures are unchanged in comparison to panels A and B of Table 3.

Life expectancies vary across government office regions of England and Wales. ${ }^{22}$ The life expectancy of people living in southern England tends to be higher than elsewhere (ONS 2014) exposing ERM providers to substantial longevity risk. Therefore, the risk analysis of equity release mortgages must also account for regional mortality experiences. In the absence of the data on death rates by region, we used the latest regional standardised mortality ratios (SMR) produced by ONS for the female population to scale mortality in order to examine the effect of regional variations in life expectancy on ERM pricing. ${ }^{23}$

Table 5 gives revised estimates for the risk measures accounting for longevity risk. In comparison to Table 3, the chance of NNEG and the value of the NNEG risk declines slightly in regions with higher mortality such as the North. For example, an increase of $14 \%$ and $10 \%$ in the North East and West respectively reduces the value of the NNEG marginally because the loan grows over a shorter duration due to lower life expectancy. Areas with lower mortality experiences behave in the opposite manner. The regional profile of the risk measures reported in Table 5 is still apparent. In particular, risk in the North is as high as earlier and is lower in the South than elsewhere. Although low longevity correlates with low house price growth, the loan in areas such as the North East still outstrips the house value over a slightly shorter horizon. Therefore, similar to Hosty et al. (2008), we argue that properties with low price growth rates may still invoke NNEG even if the borrower does not live significantly beyond her average life expectancy.

In the UK, equity release on buy-to-lets is possible although certain restrictions apply (for example on the types of property eligible) and not all lenders provide this product. It would be better to exclude these but unfortunately our data does not distinguish between buy-to-lets and power sales/repossessions. Nevertheless, we have re-estimated our results excluding these transactions as a further test of robustness in the Supplementary Appendix 3. Estimates are seen to be very similar and our conclusions remain unchanged.

\section{Solvency Capital}

In this section, we evaluate the risk metrics $\mathrm{VaR}$ and $\mathrm{CVaR}$ used to estimate capital adequacy. In the UK, insurance companies must maintain $99.5 \% \mathrm{VaR}$ of their bestestimate liabilities to remain solvent. Assessing these risk metrics are fundamental to estimating solvency capital requirements under Solvency II (Lee et al. 2018; Kenny et al. 2018).

The simulation model was re-estimated to produce regional empirical distributions of the discounted value of net cash flows using eq. (5). The VaR and CVaR results are presented in Table 6 where positive values signify low risk implying no need for firms

\footnotetext{
${ }^{22}$ According to ONS forecasts, the life expectancy for a 65-year old female in 2010-2012 is 20 years if she lives in the North East, 20.2 (North West), 20.5 (Yorkshire and Humber), 21.0 (East Midlands), 21.0 (West Midlands), 21.5 (East England), 21.7 (London), 21.6 (South East), 21.7 (South West) and 20.6 years in Wales (ONS 2014).

23 This is similar to Li et al. (2010) who analyse the sensitivity of NNEG to higher and lower mortality rates by assuming that the actual mortality rate is $20 \%$ less or more than the projected mortality rate.
} 
Table 3 Regional variation in risk measures

\begin{tabular}{|c|c|c|c|c|c|c|c|c|c|}
\hline \multirow[t]{2}{*}{ Region } & \multicolumn{3}{|c|}{ Panel A: LTV $=30 \%$} & \multicolumn{3}{|c|}{ Panel B: LTV $=40 \%$} & \multicolumn{3}{|c|}{ Panel C: LTV $=60 \%$} \\
\hline & $\begin{array}{l}\text { Chance } \\
\text { of } \\
\text { NNEG }\end{array}$ & $\begin{array}{l}\text { NNEG } \\
\text { (£) }\end{array}$ & $\begin{array}{l}\text { MIP } \\
(\pi)\end{array}$ & $\begin{array}{l}\text { Chance } \\
\text { of } \\
\text { NNEG }\end{array}$ & $\begin{array}{l}\text { NNEG } \\
(\mathfrak{f})\end{array}$ & $\operatorname{MIP}(\pi)$ & $\begin{array}{l}\text { Chance } \\
\text { of } \\
\text { NNEG }\end{array}$ & $\begin{array}{l}\text { NNEG } \\
\text { (£) }\end{array}$ & $\operatorname{MIP}(\pi)$ \\
\hline North East & $30 \%$ & 9351 & $0.68 \%$ & $36 \%$ & 15,540 & $0.85 \%$ & $45 \%$ & 31,084 & $1.14 \%$ \\
\hline North West & $16 \%$ & 3439 & $0.25 \%$ & $23 \%$ & 7018 & $0.38 \%$ & $36 \%$ & 18,072 & $0.66 \%$ \\
\hline Yorks. \& Hum. & $27 \%$ & 8588 & $0.63 \%$ & $33 \%$ & 14,276 & $0.78 \%$ & $42 \%$ & 28,711 & $1.05 \%$ \\
\hline E Midlands & $25 \%$ & 8098 & $0.59 \%$ & $31 \%$ & 13,414 & $0.73 \%$ & $40 \%$ & 26,976 & $0.99 \%$ \\
\hline W Midlands & $13 \%$ & 2840 & $0.21 \%$ & $19 \%$ & 5920 & $0.32 \%$ & $32 \%$ & 15,720 & $0.58 \%$ \\
\hline East England & $6 \%$ & 1103 & $0.08 \%$ & $11 \%$ & 2708 & $0.15 \%$ & $22 \%$ & 8906 & $0.32 \%$ \\
\hline London & $0.6 \%$ & 56 & $0.00 \%$ & $2 \%$ & 246 & $0.01 \%$ & $7 \%$ & 1792 & $0.07 \%$ \\
\hline South East & $3 \%$ & 480 & $0.03 \%$ & $7 \%$ & 1489 & $0.08 \%$ & $19 \%$ & 6500 & $0.24 \%$ \\
\hline South West & $8 \%$ & 1573 & $0.11 \%$ & $14 \%$ & 3674 & $0.20 \%$ & $25 \%$ & 11,230 & $0.41 \%$ \\
\hline Wales & $9 \%$ & 1819 & $0.13 \%$ & $15 \%$ & 4175 & $0.23 \%$ & $28 \%$ & 12,488 & $0.46 \%$ \\
\hline England \& Wales & $9 \%$ & 1645 & $0.12 \%$ & $15 \%$ & 3855 & $0.21 \%$ & $27 \%$ & 11,849 & $0.43 \%$ \\
\hline
\end{tabular}

Notes: Analysis based on over ten thousand Monte Carlo simulations. Initial house value equals median of the price paid on residential properties transacted in England \& Wales. The column 'Chance of NNEG' shows the probability of the guarantee becoming active. For each value of the termination date $T_{x}$ the values of the outstanding loan and the house net of the transaction cost are compared to assess the number of cases in which the NNEG is prompted. The columns NNEG and MIP are expected values of the distribution of the value of the NNEG and the mortgage insurance premium rate. For each region, the house value at the start of the contract is the 2016 median of the price paid on residential property transactions in England and Wales as reported by the UK Land Registry data i.e. $£ 215,000$

to maintain reserves of risk-adjusted capital. To account for all forms of risk in this particular set of calculations, the loan accumulated at a variable rate using one-quarter risk-free rates based on the Cox-Ingersoll-Ross model. We also applied annualised premium rates of $1.5 \%, 2 \%$ and $2.5 \%$ for the three loan-to-value ratios. ${ }^{24}$ There were no changes made to other valuation parameters.

It is evident from Table 6 that the $\mathrm{VaR}$ and CVaR in regions where the NNEG is more likely, mainly the North and the Midlands (from Table 3), are high resulting in greater solvency requirements and consequently less supply of ERMs. We find that for a typical borrower from the North East, there is a $99.5 \%$ chance that the present value of a provider's loss would not exceed $£ 24,299$ at $30 \%$ LTV and if the loss exceeds this figure the expected shortfall would be $£ 26,169$ (panel A). While a zero VaR in the South East and London implies that payoffs in these regions are always likely to be positive and very little capital is required. We also observe that the capital requirement increases with LTVs (panels B and C). Solvency requirements increase in all regions

\footnotetext{
${ }^{24}$ In the UK, the interest rates charged on ERMs include an amount to cover for the cost of the NNEG and other factors such as the long-term, illiquid nature of ERMs and lack of marketability of the asset (Kenny et al. 2018). Andrews and Oberoi (2015) suggest that the NNEG cost varies between 170 and 185 basis points for a total annual charge and administrative charge of 420 basis points. Current interest rates in the market are around $6.2 \%$ and increase with LTVs (ERC 2018).
} 
especially in the North. Therefore, the risk management of ERMs becomes more costly from a provider's perspective with increasing LTVs raising further concerns over the market being able to support high LTV equity release products.

\section{Government Subsidies}

The analysis thus far has established that providers have little incentive to provide ERMs outside of London and the South East. Therefore, a national policy of promoting housing as a means for funding consumption in later life would require subsidies to encourage ERM provision in these regions. In order to estimate the cost of such subsidies, we assume that the level of provider's expected return in every region should be at levels in the South East. ${ }^{25}$ Using the same simulations as in Table 3, the time to maturity, the outstanding loan amount at that time and appreciated value of the home net of transaction costs are used to calculate the average realised return on the initial loan amount. The average rates of returns in the South East $\left(\overline{r_{S E}}\right)$ were $5.96 \%$ pa (for $\mathrm{LTV}=30 \%$ ) and $5.90 \%$ pa (for LTV $=40 \%$ ). The difference between this figure and the average rates of return calculated for every other region $i\left(\overline{r_{i}}\right)$ is given in the first column of Table 7 for LTV of $30 \%$. For example, the difference between the rate of return earned in the South East and the North East at 30\% LTV is $1.34 \%$ pa.

By assuming that the government pays this difference as a subsidy, the present value of the amount of subsidy $\left(S_{i}\right)$ per ERM in region $i$ is calculated as

$$
S_{i}=L_{0}\left(\exp \left(\left(\overline{r_{S E}}-\overline{r_{i}}\right) \times t\right)-1\right) \times v^{t}
$$

where $L_{0}$ is the initial loan amount, $t$ is the time to maturity and $v$ is the discount factor calculated using a quarterly discount rate of $0.67 \%$ derived from the British Government 20-year nominal zero coupon bond yield rate at the end of 2015. These values are given in the second column for each region.

The results show that, as expected, East of England and the South West require little support and the average subsidy value is about $1 \%$ of the initial loan amount at both lower and higher LTVs. However, the ratio of the subsidy to the initial loan amount is significant elsewhere. In fact, subsidies are infeasibly high in the North East and Yorkshire \& Humber. These results imply that the government would have to fund up to one-sixth of the initial loan amount if the LTV was $30 \%$ and one-fourth if it was $40 \%$ to make rates of return in the North as attractive as in the South East. ${ }^{26}$ This would be an enormous cost to the government if all eligible 65 -year old borrowers were issued an ERM. $^{27}$

\footnotetext{
${ }^{25}$ Our estimated rate of return for the South East is $5.96 \%$. Although this estimate would appear high, it is comparable to returns in the UK commercial property sector over the last ten years. The market in the South East is the most active in the UK and therefore we presume that rates of return in all regions would need to be at this level to attract providers into the market.

${ }^{26}$ At LTV $=30 \%$, the initial loan amount is $0.3 \times £ 215,000=£ 64,500$ and the average subsidy in the North East is $£ 11,556$ or 0.18 as a proportion of the initial loan amount.

${ }^{27}$ A limitation of these figures is that they do not take into consideration the effect of natural hedges taking place across regions that may positively influence the total amount of government subsidy.
} 
Table 4 Regional variation in risk measures based on region-specific initial house values

\begin{tabular}{|c|c|c|c|c|c|c|c|}
\hline \multirow[t]{2}{*}{ Region } & \multirow{2}{*}{$\begin{array}{l}\text { Median House } \\
\text { Prices }(£)\end{array}$} & \multicolumn{3}{|c|}{ Panel A: LTV $=30 \%$} & \multicolumn{3}{|c|}{ Panel B: LTV $=40 \%$} \\
\hline & & $\begin{array}{l}\text { Chance } \\
\text { of NNEG }\end{array}$ & NNEG (£) & $\operatorname{MIP}(\pi)$ & $\begin{array}{l}\text { Chance } \\
\text { of NNEG }\end{array}$ & NNEG (£) & $\operatorname{MIP}(\pi)$ \\
\hline North East & 127,995 & $29 \%$ & 5593 & $0.69 \%$ & $36 \%$ & 9266 & $0.85 \%$ \\
\hline North West & 145,000 & $15 \%$ & 2251 & $0.24 \%$ & $21 \%$ & 4609 & $0.37 \%$ \\
\hline Yorks. \& Humber & 146,500 & $26 \%$ & 5650 & $0.60 \%$ & $32 \%$ & 9422 & $0.76 \%$ \\
\hline E Midlands & 165,000 & $25 \%$ & 6229 & $0.59 \%$ & $30 \%$ & 10,306 & $0.74 \%$ \\
\hline W Midlands & 167,500 & $13 \%$ & 2267 & $0.21 \%$ & $19 \%$ & 4679 & $0.33 \%$ \\
\hline East England & 255,000 & $5 \%$ & 902 & $0.05 \%$ & $8 \%$ & 2282 & $0.10 \%$ \\
\hline London & 435,000 & $0.6 \%$ & 97 & $0.00 \%$ & $2 \%$ & 493 & $0.01 \%$ \\
\hline South East & 292,500 & $3 \%$ & 586 & $0.03 \%$ & $7 \%$ & 1899 & $0.08 \%$ \\
\hline South West & 227,000 & $8 \%$ & 1598 & $0.11 \%$ & $13 \%$ & 3728 & $0.19 \%$ \\
\hline Wales & 145,000 & $9 \%$ & 1158 & $0.12 \%$ & $15 \%$ & 2681 & $0.22 \%$ \\
\hline England \& Wales & 215,000 & $9 \%$ & 1645 & $0.12 \%$ & $15 \%$ & 3855 & $0.21 \%$ \\
\hline
\end{tabular}

Notes: The value of the house at the start of the contract equals the 2016 median of the price paid on residential property transactions in the region as reported by the UK Land Registry data

\section{Conclusion}

Elderly housing assets in the UK continue to be the focus of policy debates about how to pay for social care and how to support retirement incomes. Accessing this property wealth through equity release mortgages is central in many policy proposals. Demand for equity release is similar in all parts of the country. However, we demonstrate in this paper that due to their inherent riskiness providers cannot profitably supply these products in many UK regions.

The main risk faced by providers is the No Negative Equity Guarantee (NNEG). For each region, we model the probability of negative equity, the NNEG value and the cost to the consumer in the form of a higher mortgage insurance premium. We find that whereas the NNEG is rarely invoked in the South East where house prices are high approximately one-third of equity release contracts are likely to end up in negative equity in the North where house prices have grown much more slowly. This should theoretically translate into customers paying significantly higher mortgage insurance premium rates but in practice there is no regional variation in NNEG risk costs charged to borrowers. We therefore conclude that the spatial distribution of ERM take-up we observe is not explained by variations in demand but by regional variations in house price risk faced by the ERM provider. Our results are seen to be robust to a number of checks including adjustments for regional variations in mortality and initial house price value. Further work could also consider modelling the ERM borrower as a couple as well as modelling non-mortality related causes of contract termination although other studies indicate that results would not be significantly different to those presented here.

Most UK equity release providers are insurance companies as these products match the cashflows of their long-term liabilities. The European Union Solvency II Directive harmonises insurance regulation across the EU and in particular specifies the amount of 


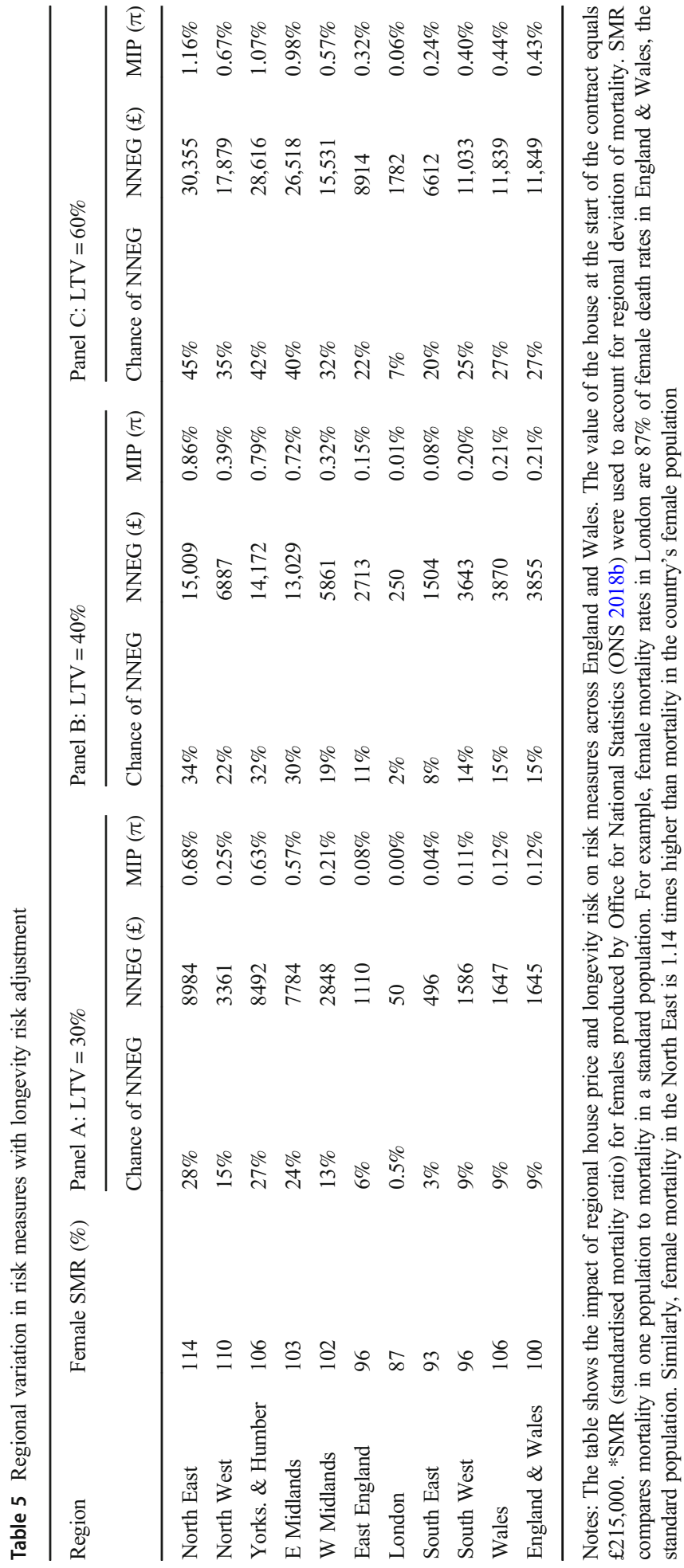


Table 6 Regional 99.5\% VaR and CVaR

\begin{tabular}{|c|c|c|c|c|c|c|}
\hline \multirow[t]{2}{*}{ Region } & \multicolumn{2}{|c|}{ Panel A: LTV $=30 \%$, in $£$} & \multicolumn{2}{|c|}{ Panel B: LTV $=40 \%$, in $£$} & \multicolumn{2}{|c|}{ Panel C: LTV $=60 \%$, in $£$} \\
\hline & VaR & CVaR & VaR & CVaR & VaR & $\mathrm{CVaR}$ \\
\hline North East & $-24,299$ & $-26,169$ & $-34,234$ & $-36,557$ & $-55,273$ & $-58,417$ \\
\hline North West & $-14,121$ & $-17,295$ & $-22,631$ & $-26,825$ & $-42,814$ & $-47,310$ \\
\hline Yorks. \& Humber & $-23,461$ & $-25,328$ & $-33,161$ & $-35,460$ & $-53,653$ & $-56,837$ \\
\hline E Midlands & $-23,578$ & $-25,809$ & $-33,011$ & $-35,720$ & $-53,648$ & $-56,673$ \\
\hline W Midlands & $-11,434$ & $-15,015$ & $-19,783$ & $-24,100$ & $-39,379$ & $-43,865$ \\
\hline East England & -276 & -3748 & -7903 & $-11,578$ & $-25,545$ & $-30,043$ \\
\hline London & 0 & 0 & 0 & -2694 & 0 & -7822 \\
\hline South East & 0 & -3267 & 0 & -5008 & $-14,875$ & $-20,851$ \\
\hline South West & -4642 & -8989 & $-13,077$ & $-17,175$ & $-31,750$ & $-36,430$ \\
\hline Wales & -5333 & -9601 & $-13,668$ & $-18,666$ & $-32,316$ & $-38,245$ \\
\hline England \& Wales & -4635 & -9123 & $-12,546$ & $-17,977$ & $-31,067$ & $-37,620$ \\
\hline
\end{tabular}

Notes: The value at risk $(\mathrm{VaR})$ equals the $(100-99.5=0.5)^{\mathrm{th}}$ percentile of the ordered distribution of the discounted net final payoff/economic value. The conditional value at risk (CVaR) equals the average of the values below the $0.5 \% \mathrm{VaR}$ threshold. A positive value of the $\mathrm{VaR}$ and $\mathrm{CVaR}$ implies a positive economic value of the indicating no need for the provider to set aside risk-based capital. Annualised mortgage insurance premium equals $1.5 \%$ for an LTV of $30 \%, 2 \%$ at $40 \%$ LTV and $2.5 \%$ at $60 \%$ LTV. The value of the house at the start of the contract equals $£ 215,000$

capital that insurance companies must hold to reduce the risk of insolvency. Under this regime, the UK Prudential Regulation Authority requires companies to determine the

Table 7 Rate and value of subsidy per scheme

\begin{tabular}{|c|c|c|c|c|}
\hline \multirow[t]{2}{*}{ Region } & \multicolumn{2}{|l|}{ Panel A: LTV $=30 \%$} & \multicolumn{2}{|l|}{ Panel B: LTV $=40 \%$} \\
\hline & $\begin{array}{l}\text { Subsidy rate } \\
\text { (annualised) } \overline{r_{S E}}-\overline{r_{i}}\end{array}$ & Subsidy $(£) S_{i}$ & Subsidy rate (annualised) $\overline{r_{S E}}-\overline{r_{i}}$ & Subsidy (£) $S_{i}$ \\
\hline North East & $1.34 \%$ & 11,556 & $1.70 \%$ & 20,571 \\
\hline North West & $0.33 \%$ & 2550 & $0.51 \%$ & 5311 \\
\hline Yorks. \& Humber & $1.28 \%$ & 11,021 & $1.61 \%$ & 19,232 \\
\hline East Midlands & $1.20 \%$ & 10,172 & $1.49 \%$ & 17,599 \\
\hline West Midlands & $0.27 \%$ & 2031 & $0.40 \%$ & 4095 \\
\hline East England & $0.07 \%$ & 483 & $0.11 \%$ & 1056 \\
\hline London & $0.00 \%$ & - & $0.00 \%$ & - \\
\hline South East & $0.00 \%$ & - & $0.00 \%$ & - \\
\hline South West & $0.11 \%$ & 792 & $0.18 \%$ & 1771 \\
\hline Wales & $0.14 \%$ & 1041 & $0.23 \%$ & 2267 \\
\hline
\end{tabular}

Note: The difference between the average rate of return on ERM loans in region $i\left(\bar{r}_{i}\right)$ and the average rate of return in the south east $\left(\bar{r}_{S E}\right)$ is the subsidy rate. The subsidy $\left(S_{i}\right)$ is the amount required to make rates of return for an ERM in region $i$ the same as in the South East. The subsidy in London is a negative number hence effectively zero. The initial value of the house equals $£ 215,000$ 
economic value of ERMs adjusting for risk in order to estimate solvency capital requirements. We calculate the $\mathrm{VaR}$ and $\mathrm{CVaR}$ risk metrics for these economic values to further demonstrate the implications of providing these products in areas of low house price growth. Our results show VaR and CVaR are much higher in the North implying higher capital requirements while practically no solvency capital is required in London and the South. Solvency II requirements therefore provide a further disincentive to supply ERMs outside areas of high house price growth.

We also demonstrate that the government policy focus on equity release as a means of relieving the financial burden of government support for social care and providing the state pension is misplaced. Other studies have argued for government intervention in terms of subsidising the risk of the NNEG. We find that that government would have to fund up to one-sixth of the initial loan amount if the LTV was 30\% and one-fourth if it was $40 \%$ to make rates of return in the North as attractive as in the South-East. This would be excessively costly if all eligible 65 -year old borrowers were issued an ERM.

The model used in this paper relies on longevity and house price growth models based on available data as well as parameter values reflecting current market conditions. However, life spans and elder morbidity are changing in ways that are hard to accurately predict. House price growth has recently slowed down in the UK especially in London. Also, the demand for ERM is changing due to pension reforms and a decline in defined benefit schemes as well as the imminent maturing of a larger number of interest-only mortgages sold in the 1990's. Recent increased supply is also driving down ERM interest rates and hence the risk of negative equity. These factors will affect future supply and demand for ERMs.

Open Access This article is licensed under a Creative Commons Attribution 4.0 International License, which permits use, sharing, adaptation, distribution and reproduction in any medium or format, as long as you give appropriate credit to the original author(s) and the source, provide a link to the Creative Commons licence, and indicate if changes were made. The images or other third party material in this article are included in the article's Creative Commons licence, unless indicated otherwise in a credit line to the material. If material is not included in the article's Creative Commons licence and your intended use is not permitted by statutory regulation or exceeds the permitted use, you will need to obtain permission directly from the copyright holder. To view a copy of this licence, visit http://creativecommons.org/licenses/by/4.0/.

\section{References}

Alai, D. H., Chen, H., Cho, D., Hanewald, K., \& Sherris, M. (2014). Developing equity release markets: Risk analysis for reverse mortgages and home reversions. North American Actuarial Journal, 18(1), 217-241.

Andrews, D., \& Oberoi, J. (2015). Home equity release for long-term care financing: An improved market structure and pricing approach. Annals of Actuarial Science, 9(1), 85-107.

Banks, J., Blundell, R., Oldfield, Z. and Smith, J. P. (2010). Housing price volatility and downsizing in later life. In Research Findings in the Economics of Aging (pp. 337-379). University of Chicago Press.

BBC (2019). House price growth at six-year low. BBC. https://www.bbc.co.uk/news/business.

Bernanke, B. S., Boivin, J., \& Eliasz, P. (2005). Measuring the effects of monetary policy: A factor-augmented vector autoregressive (FAVAR) approach. The Quarterly Journal of Economics, 120(1), 387-422.

Bracke, P., Pinchbeck, E. W., \& Wyatt, J. (2018). The time value of housing: Historical evidence on discount rates. The Economic Journal, 128(613), 1820-1843.

Chandler, D. \& Disney, R. (2014). Measuring house prices: a comparison of different indices, Institute for Fiscal Studies IFS Briefing Note BN146.

CPS (2019). Fixing the care crisis, Centre for Policy Studies. www.cps.org.uk. 
Chen, H., Cox, S. H., \& Wang, S. S. (2010). Is the home equity conversion mortgage in the United States sustainable? Evidence from pricing mortgage insurance premiums and non-recourse provisions using the conditional Esscher transform. Insurance: Mathematics and Economics, 46(2), 371-384.

Chen, T., \& Harding, J. P. (2016). Changing tastes: Estimating changing attribute prices in hedonic and repeat sales models. The Journal of Real Estate Finance and Economics, 52(2), 141-175.

Cox, J. C., Ingersoll, J. E., \& Ross, S. A. (1985). A theory of the term structure of interest rates. Econometrica, 53(2), 385-407.

Das, S., Gupta, R., \& Kabundi, A. (2010). The blessing of dimensionality in forecasting real house price growth in the nine census divisions of the US. Journal of Housing Research, 19(1), 89-109.

Davidoff, T. (2015). Can "high costs" justify weak demand for the home equity conversion mortgage? The Review of Financial Studies, 28(8), 2364-2398.

de Haan, J. \& Diewert, E. (2013). Hedonic regression methods. In OECD et al. (Ed.) Handbook on Residential Property Price Indices (pp. 50-64). Luxembourg: Eurostat.

ERC. (2018). Equity release council spring 2018 market report. Northants: Equity Release Council.

ERC. (2019). Equity release council spring 2019 market report. Northants: Equity Release Council.

FCA (2016). Ageing population and financial services, Financial Conduct Authority Discussion Paper 16/1.

FCA (2017). Ageing Population and Financial Services, Occasional Paper 31. www.fca.org.uk.

FCA (2018). Residential interest only mortgages - Volumes, concentrations and maturity horizons. www.fca. org.uk

Financial Times (2019). UK house price forecast are drastically downgraded. Financial Times. https://www.ft. com/content/.

Forder, J. \& Fernandez, J. (2011). Length of stay in care homes. Report commissioned by Bupa care services, PSSRU discussion paper 2769. http://eprints.lse.ac.uk.

Fox O'Mahony, L. \& Overton, L. (2015). The future of the UK equity release market: Consumer insights and stakeholder perspectives. University of Essex/The Leverhulme Trust.

French, D., McKillop, D., \& Sharma, T. (2018). What determines UK housing equity withdrawal in later life? Regional Science and Urban Economics, 73, 143-154.

Halifax (2016). Halifax House Price Index Methodology Guide. http://content.markitcdn.com.

Haurin, D., Ma, C., Moulton, S., Schmeiser, M., Seligman, J., \& Shi, W. (2016). Spatial variation in reverse mortgages usage: House price dynamics and consumer selection. The Journal of Real Estate Finance and Economics, 53(3), 392-417.

Hilber, C.A. (2015). UK Housing and Planning Policies: the evidence from economic research. http://eprints. 1se.ac.uk/61745/1/ea033.pdf.

Hill, R. J. (2013). Hedonic price indexes for residential housing: A survey, evaluation and taxonomy. Journal of Economic Surveys, 27(5), 879-914.

Hosty, G., Groves, S., Murray, C., \& Shah, M. (2008). Pricing and risk capital in the equity release market. British Actuarial Journal, 14(1), 41-91.

IFoA (2014). Lifetime mortgages - a good and appropriate investment for life companies with annuity liabilities?. Institute and Faculty of Actuaries, UK.

Jackson, D. A. (1993). Stopping rules in principal components analysis: A comparison of Heuristical and statistical approaches. Ecology, 74(8), 2204-2214.

Kenny, T., Golding, C., Craske, G., Dobinson, A., Gunter, S., Griffiths, O., et al. (2018). Actuarial Management of Equity Release Mortgages - current practices and issues in the actuarial management of ERMs in the UK.

Key Retirement. (2018). UK equity release market monitor, full year 2018. Preston: Key Retirement.

Lee, R. D., \& Carter, L. R. (1992). Modelling and forecasting US mortality. Journal of the American Statistical Association, 87(419), 659-671.

Lee, Y., Kung, K., \& Liu, I. (2018). Profitability and risk profile of reverse mortgages: A cross-system and cross-plan comparison. Insurance: Mathematics and Economics, 78, 255-266.

Lee, Y., Wang, C., \& Huang, H. (2012). On the valuation of reverse mortgages with regular tenure payments. Insurance: Mathematics and Economics, 51(2), 430-441.

Li, J. S., Hardy, M. R., \& Tan, K. S. (2010). On pricing and hedging the no-negative-equity guarantee in equity release mechanisms. The Journal of Risk and Insurance, 77(2), 499-522.

Lords (2013). Ready for ageing? House of Lords Select Committee on Public Service and Demographic Change. HL Paper, vol. 140.

Moulton, S., Haurin, D. R., \& Shi, W. (2015). An analysis of default risk in the home equity conversion mortgage (HECM) program. Journal of Urban Economics, 90, 17-34. 
Nakajima, M. and Telyukova, I. A., (2014). Reverse mortgage loans: A quantitative analysis. Research department, Federal Reserve Bank of Philadelphia. Working paper no. 14-27. Available at: SSRN 2494405.

Nakajima, M., \& Telyukova, I. A. (2017). Reverse mortgage loans: A quantitative analysis. The Journal of Finance, 72(2), 911-950.

ONS (2019). Guide to calculating national life tables: Explanation of the methodology used to create the national life tables. Office for National Statistics, UK.

ONS (2018a). House prices in the north east of England: 2007 to 2017. Office for National Statistics,

ONS (2018b). User guide to mortality statistics. Office for National Statistics, UK.

ONS (2017). Past and projected data from the period and cohort life tables, 2016-based, UK: 1981 to 2066. Office for National Statistics, UK.

ONS (2014). Life expectancy at birth and at age 65 by local areas in the United Kingdom: 2006-08 to 201012. Office for National Statistics, UK.

PRA (2018). Solvency II: Equity release mortgages. Consultation paper CP13/18. Prudential Authority Regulation, London.

PRA (2016). Solvency II: Matching adjustment - illiquid unrated assets and equity release mortgages. Consultation paper CP48/16. Prudential Regulation Authority, London.

Pu, M., Fan, G.-Z., \& Deng, Y. (2014). Breakeven determination of loan limits for reverse mortgages under information asymmetry. The Journal of Real Estate Finance and Economics, 48(3), 492-521.

Shao, A. W., Hanewald, K., \& Sherris, M. (2015). Reverse mortgage pricing and risk analysis allowing for idiosyncratic house price risk and longevity risk. Insurance: Mathematics and Economics, 63, 76-90.

Shan, H. (2011). Reversing the trend: The recent expansion of the reverse mortgage market. Real Estate Economics, 39(4), 743-768.

Sharma, T., McKillop, D., \& French, D. (2018). Pensions, housing and mortgage markets in the UK. In M. Eckardt et al. (Eds.), Old-age provision and homeownership-fiscal incentives and other public policy options (pp. 107-142). Cham: Springer.

Sherris, M. and Sun, D. (2010). "Risk based capital and pricing for reverse mortgages revisited", UNSW Australian School of Business Research Paper, working paper no. 2010ACTL04.

Swain, R. \& Swallow, D. (2015). The prudential regulation of insurers under solvency II. Bank of England Quarterly Bulletin, Q2.

Tsay, R. S. (2010). Multivariate time series analysis and its applications. In balding et al. (Ed.) Analysis of Financial Time Series (pp. 399-415). New Jersey: John Wiley \& Sons, Inc.

Tunaru, R. and Quaye, E. (2019). UK equity release mortgages: A review of the no-negative equity guarantee, Actuarial Research Centre/Institute and Faculty of Actuaries, February. https://www.actuaries.org.uk.

Publisher's Note Springer Nature remains neutral with regard to jurisdictional claims in published maps and institutional affiliations. 